\title{
A Epistemologia Genética em um Experimento Virtual Imersivo 3D de Magnetismo
}

\section{Genetic Epistemology in 3D Virtual Immersive Magnetism Experiment}

\author{
Valter A. Ferreira - PPGIE - UFRGS - valter.unipampa@ gmail.com \\ Priscila C. Nicolete - PPGIE - UFRGS - priscilanicolete@ hotmail.com \\ Liane M. R. Tarouco - PPGIE - UFRGS - liane@ penta.ufrgs.br \\ Fernando Becker - PPGIE - UFRGS - fbeckerufrgs@ gmail.com
}

\begin{abstract}
Resumo: Este trabalho trata do desenvolvimento de um experimento virtual imersivo 3D de magnetismo elaborado na plataforma OpenSim. A fundamentação teórica encontra-se na Epistemologia Genética, a coleta de dados inspirou-se no Método Clínico de Piaget e a análise foi realizada com base nos estudos de Piaget e Inhelder sobre o pensamento do adolescente. Os dados foram obtidos pela gravação audiovisual da apliação da entrevista clínica ao longo das simulações virtuais. Os resultados demonstraram a viabilidade da criação de experimentos virtuais imersivos $3 \mathrm{D}$ de magnetismo sob a ótica da teoria de Piaget, além de apontar para o uso do pensamento formal por parte dos sujeitos entrevisados.
\end{abstract}

Palavras-chave: Laboratório Virtuais Imersivos 3D; Epistemologia Genética; Ensino de Física.

Abstract: This work deals with the development of an immersive 3D virtual experiment
of magnetism elaborated on the OpenSim platform. The theoretical basis is found in
Genetic Epistemology, the data collection was inspired by the Clinical Method of Piaget
and the analysis was carried out based on the studies of Piaget and Inhelder on the
thought of the adolescent. The data were obtained by the audiovisual recording of the
clinical interview application during the virtual simulations. The results demonstrated
the feasibility of creating 3D immersive virtual magnetism experiments under the
perspective of Piaget's theory, besides pointing to the use of formal thinking by the
interviewed subjects.

Keywords: Virtual Immersive 3D Laboratory; Genetic Epistemology; Physics

Teaching.

\section{INTRODUÇÃO}

De acordo com os Parâmetros Curriculares Nacionais para o Ensino Médio (BRASIL, 1999b), os conhecimentos de Eletricidade e Magnetismo são importantes para a obtenção de uma leitura adequada do mundo da informação e da comunicação. No entanto, estudos indicam dificuldades de entendimento dos conceitos deste campo da Física, pois os fenômenos não são visíveis e requerem um elevado grau de abstração para serem compreendidos. Macedo (2000) aponta a dificuldade dos estudantes em visualizar o campo magnético no espaço tridimensional e apregoa uma estratégia que envolva o uso de ferramentas computacionais interativas para beneficiar a construção conceitual. Na mesma linha, Tavares (2008) apresenta um estudo com universitários sobre os obstáculos na construção de modelos mentais de superfície gaussiana e fluxo de campo elétrico, no qual tais conceitos são relegados a imagens isoladas sem generalização.

Por sua vez, Melo (2010) ressalta que a educação brasileira não tem acompanhado o ritmo de desenvolvimento das inovações digitais, demonstrando a importância da 
criação de alternativas tecnológicas capazes de promover a construção de conhecimentos e o desenvolvimento da cidadania. Entre as aplicações educacionais estão a dos mundos virtuais imersivos 3D, na qual Greys (2012) elaborou um ambiente de aprendizagem, empregando o metaverso Second Life, cujo objetivo foi estudar a colisão entre dois corpos em um parque de diversões. Neste contexto, o usuário interagia com um carro choque e era instigado a explicar os conceitos físicos relacionados ao fenômeno. Em outro estudo, Herpich e Tarouco (2016) criaram, no ambiente OpenSim, um laboratório de Eletromagnetismo para investigar o aspecto de engajamento dos usuários. As atividades pedagógicas foram integradas a um material de consulta audiovisual e a um experimento de simulação da Bobina de Tesla. O cenário estimulava o usuário a interagir com um painel de controle para comandar a simulação e configurar alguns parâmetros de desempenho, possibilitando o contato com os seguintes eventos elétricos: rigidez dielétrica do ar, ionização de gases e relâmpagos artificiais.

A utilização destas tecnologias procurou proporcionar uma mudança nas práticas pedagógicas tradicionais - na qual os estudantes costumam ser apenas espectadores para uma aprendizagem ativa com oportunidade de construção de conhecimento. Nesse sentido, a teoria desenvolvida por Jean Piaget (1978) destaca que o conhecimento não provém unicamente do meio externo (objeto), nem é inerente ao sujeito, mas que surge da relação entre eles, assim sendo, só haverá construção de conhecimento por meio da ação do sujeito sobre o objeto de conhecimento.

Além disso, para Piaget (1976), a construção do conhecimento não parte do zero, não principia no sujeito ou no objeto ou configura mero registro, mas é fruto de uma estrutura em constante diferenciação, com base nos esquemas mentais anteriormente elaborados. Com isso, ressalta-se o interesse no estudo dos experimentos virtuais imersivos 3D como estratégia para auxiliar na formação das abstrações necessárias ao efetivo processo de equilibração cognitiva e a possível tomada de consciência por parte do sujeito.

Então, aliando o potencial dos metaversos para a construção do conhecimento, como uma alternativa complementar às atividades de um laboratório real (minimização de custos e facilidade de acesso a qualquer hora de qualquer lugar) à Epistemologia Genética de Jean Piaget, como o substrato básico para a compreensão dos processos relacionados ao equilíbrio cognitivo (assimilação e acomodação), o presente artigo apresenta a seguinte questão de pesquisa: Como desenvolver um experimento de Magnetismo, com base no grupo INRC de Piaget (Identidade, Negação, Recíproca, Correlação) do estádio do pensamento formal?

Nesta situação, pretende-se estimular o "fazer para compreender", onde o sujeito é desafiado a uma experiência virtual construída com base em elementos da realidade, cuja simulação se dá através do paradigma construtivista. (PIAGET; INHELDER, 1976).

\section{EPISTEMOLOGIA GENÉTICA}

Piaget e colaboradores concentraram-se em esclarecer a questão epistemológica fundamental das relações entre técnica e ciência. Desse modo, pretendeu-se compreender como o sujeito epistêmico constrói seu conhecimento, da criança ao adulto. Com isso, Piaget (1974) descobriu a alteração da estrutura cognitiva ocorrendo de variadas maneiras em diferentes momentos da vida do sujeito e que a passagem para um nível de pensamento superior não ocorre de maneira brusca, mas através de múltiplas transições entre os estádios de desenvolvimento intelectual. Isto demanda a 
maturação biológica como condição necessária, mas não suficiente, havendo a necessidade de uma interferência externa para o avanço cognitivo.

Diante disso, no estádio denominado por Piaget como operatório-concreto, que ocorre, em média, de 2 a 11 anos de idade, as operações estão baseadas na percepção de objetos porque a capacidade de abstração ainda não está totalmente aperfeiçoada e a construção de uma lógica envolvendo classes, relações e números, progride paralelamente às noções de conservação. $O$ sujeito não se limita a uma representação imediata da realidade, mas organiza de forma operatória o mundo ao seu redor, mantendo a capacidade de abstração na dependência dos objetos concretos. (PIAGET; INHELDER, 1976).

O estádio operatório-formal (de 11 a 15 anos, em média) diferencia-se do anterior tanto pelos instrumentos de coordenação de ações quanto pela abrangência do campo de atuação, subordinando o real ao possível e considerando apenas os fatos verificados com base nas hipóteses advindas de uma situação-problema. As premissas construídas culminam na admissão de uma verdade hipotética representada não mais por objetos, mas por enunciados verbais construídos através da lógica das proposições. Isto estabelece uma estrutura capaz de operar nos dois sentidos, a partir de um conjunto de operações possíveis e de transformações que obedecem às leis da reversibilidade (PIAGET; INHELDER, 1976).

Enquanto as operações concretas atuam sobre os conteúdos empíricos da cognição, as formais operam sobre as reações do pensamento, transformando os invariantes em abstrações aplicáveis a qualquer aspecto da realidade. Assim, o sujeito pode conceber um evento em função de fatores e agir sobre a coordenação das ações ou sobre as operações abstraídas das ações, realizando a transição do raciocínio concreto para o proposicional. O caráter genérico das operações proposicionais apresenta-se de duas formas distintas, combinadas como uma "rede" de associações ou através do grupo de quatro transformações INRC (PIAGET; INHELDER, 1976).

A construção da lógica da "rede" dá-se, por exemplo, ao serem considerados os fatores $\mathrm{P}$ e Q em conjunto com $\sim \mathrm{P}$ (negação de $\mathrm{P}$ ) e $\sim \mathrm{Q}$ (negação de $\mathrm{Q}$ ), originando as quatro associações básicas: (P . Q), (P . Q), ( P . Q), ( P . Q ) que combinadas "n por n" em uma tabela-verdade, apresentam 16 combinações hipotéticas restritas a um limite superior $(\sim \mathrm{P} . \sim \mathrm{Q}) \mathrm{V}(\sim \mathrm{P} . \mathrm{Q}) \mathrm{V}(\mathrm{P} . \sim \mathrm{Q}) \mathrm{V}(\mathrm{P} . \mathrm{Q})$ (todas são verdadeiras) e um limite inferior $\sim[(\sim \mathrm{P} . \sim \mathrm{Q}) \mathrm{V}(\sim \mathrm{P} . \mathrm{Q}) \mathrm{V}(\mathrm{P} . \sim \mathrm{Q}) \mathrm{V}(\mathrm{P} . \mathrm{Q})]$ (todas são falsas), entre os quais somente algumas associações possíveis deverão ser entendidas como verdadeiras. Piaget (1978) ressalta que o sujeito do estádio formal pode construir cognitivamente as 16 combinações binárias mesmo não sendo capaz de explicitá-las.

A outra estrutura lógica do período formal apresenta uma integração entre os agrupamentos de classe e série, formando uma dupla modalidade de reversibilidade (inversão e reciprocidade). As operações proposicionais servem como instrumento para articular as quatro transformações em um único sistema, denominado de Grupo INRC. Segundo Piaget (1976), mesmo o desconhecimento das técnicas desta lógica não impede o sujeito de inter-relacionar hipoteticamente tais transformações para uma infinidade de situações.

Assim, a junção dos dois fatores $(\mathrm{P}, \mathrm{Q})$ pode ser representada como:

- Identidade: $\mathrm{I}=(\mathrm{P} V \mathrm{Q})$;

- Negação: $N=(\sim P . \sim Q)$, obtida invertendo a função e os valores dos fatores da identidade;

- Recíproca: $\mathrm{R}=(\sim \mathrm{P} \mathrm{V} \sim \mathrm{Q})$, obtida invertendo somente os valores dos fatores da identidade; 
- Correlação: $C=(P . Q)$, obtida invertendo a função e os valores dos fatores da recíproca;

Estas estruturas evidenciam o estádio formal e sua lógica pode ser empregada como uma estratégia de elaboração da dinâmica da simulação computacional. No sentido de que as coordenações de ações que levem ao êxito possam ser percorridas em sentido inverso pelo sujeito, de modo a estimular uma possível tomada de consciência e construção de conceitos.

\section{MATERIAIS E MÉTODOS}

Este estudo é caracterizado com uma pesquisa aplicada, uma vez que, estas se caracterizam pela busca da aplicação ou utilização dos conhecimentos que são adquiridos. Já em relação aos procedimentos técnicos a pesquisa consiste de um estudo de caso, pois, é adequado para a análise de processos, já que entre suas finalidades está entender a forma nas quais pessoas ou grupos sociais representam suas experiências e interatuam em diferentes situações dentro de um espaço definido de tempo (YIN, 2006). Além disso, em relação à forma de abordagem do problema definiu-se como uma pesquisa qualitativa. A coleta de dados inspirou-se no Método Clínico de Piaget e a análise foi realizada com base nos estudos de Piaget e Inhelder sobre o pensamento do adolescente.

\subsection{Desenvolvimento do mundo virtual}

A abordagem experimental deste artigo inspirou-se nos estudos de Piaget e Inhelder (1976) para compreender a estrutura cognitiva de crianças e adolescentes quando da execução de experimentos físicos. A prensa hidráulica desenvolvida por Piaget e Inhelder, por exemplo, foi abordado através de um aparato com dois vasos comunicantes, um aberto e o outro fechado com um pistão, sobre o qual foram colocadas massas para aumentar a intensidade do peso e da pressão sobre o líquido, o qual reagia em sentido contrário com uma força de mesmo módulo e direção. Neste experimento, os autores buscaram compreender como o sujeito passa do pensamento concreto para o formal ao observar não somente a simples correspondência entre o aumento do peso do pistão e o deslocamento do líquido, mas necessitando explicar o equilíbrio ocasionado pelas forças de ação e reação, as quais atuavam em um mecanismo governado pelas quatro transformações do grupo INRC.

De maneira semelhante, este artigo apresenta o desenvolvimento de um dispositivo projetado para representar o funcionamento integrado dos dois tipos de reversibilidade (inversão e reciprocidade), sendo implementado em um ambiente virtual imersivo 3D e abordando noções de Magnetismo, enquanto os de Piaget foram reais e versaram sobre Mecânica, Hidrostática e Ótica.

A elaboração do experimento também empregou os preceitos de Jonassen (1995), o qual utiliza a Epistemologia Genética para explorar as potencialidades dos mundos virtuais imersivos, propondo um ambiente construtivista cuja interatividade seja capaz de estimular o sujeito ao enfrentamento de situações-problema. Desse modo, a atividade de simulação procurou promover: a exploração, a experimentação, a construção, a colaboração e a reflexão, sendo experienciada individualmente pelo sujeito da pesquisa.

Os parâmetros levados em conta para a criação do experimento foram:

1- O objetivo do experimento; (Apresentar um experimento cujo equilíbrio físico está atrelado ao grupo INRC de Piaget) 
2- O desafio proposto; (explicar a razão do imã superior não encostar-se ao imã inferior)

3- Os procedimentos de ensaio;

4- As grandezas físicas envolvidas; (forças peso e de repulsão magnética)

5- O fato e os fatores envolvidos na manipulação experimento; (equilíbrio do imã superior e massas acrescentadas ao imã superior)

6- A relação do experimento com o grupo I N R C;

7- Os questionamentos mínimos para a aplicação do Método Clínico;

A necessidade de gerenciar positivamente os recursos audiovisuais disponíveis no ambiente virtual justifica o emprego da aprendizagem multimídia de Mayer (2001), objetivando uma experiência sensorial rica e qualificada ao longo do processo de adaptação cognitiva do sujeito.

A escolha da plataforma OpenSim (http://opensimulator.org.), ocorreu pelo fato da mesma ser disponibilizada gratuitamente e apresentar praticamente as mesmas funcionalidades do Second Life, tanto graficamente, quanto nos aspectos de fidelidade, relevância e visão de múltiplas perspectivas. Conforme Amaral (2013), este metaverso possibilita o acesso através de vários visualizadores (o escolhido foi o Singularity Viewer), pode carregar objetos externos e permite remodelar algumas características do cenário alterando um objeto chamado de "prim" (GREIS, 2012).

O experimento (figura 01) aborda a interação magnética entre dois imãs cujos polos estão estrategicamente posicionados para coincidir ou antagonizar. O equipamento está disposto da seguinte forma:

a) Dois imãs de mesmas dimensões, um fixo (posição inferior) e outro móvel (posição superior);

b) Duas hastes fixas de material não metálico por onde o imã superior poderá descer e subir livremente.

c) Duas massas de mesmo material (não metálico) e valores distintos.

d) Painel de controle com alavancas para manipulação de imãs e massas, assim como luzes de sinalização de acionamento (verde = acionamento liberado e vermelho = acionamento não permitido);

Figura 01- a) Posição inicial.

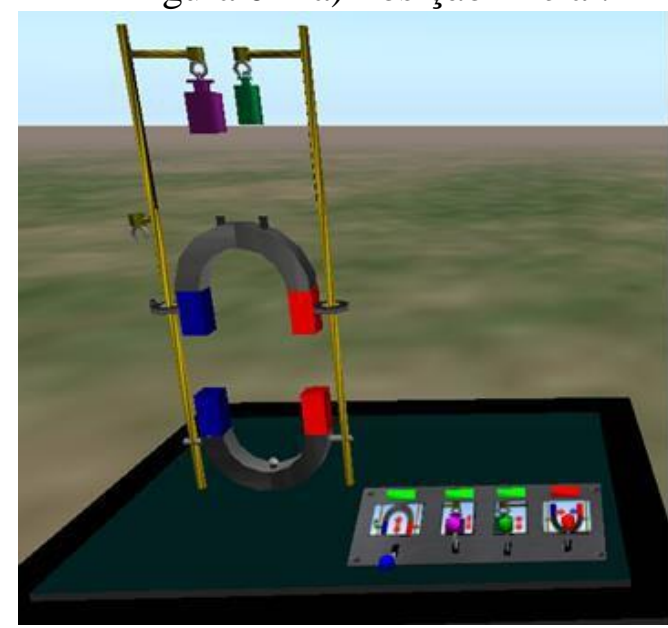

Fonte: o autor. b) Posição final.

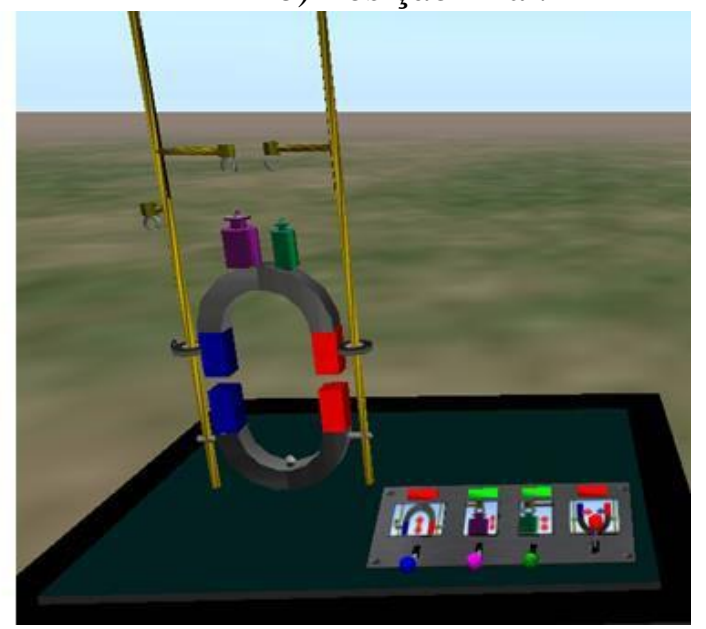

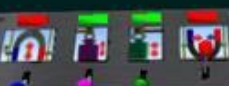

A programação foi feita em linguagem LSL, de modo que os scripts com os programas foram alocados no interior dos objetos (prims) e possuíam as mais diversas 
finalidades, desde acendimento de luzes no painel até a movimentação de palancas, massas e imãs (figura 02).

Figura 02- Script com a programação do movimento da massa M1.

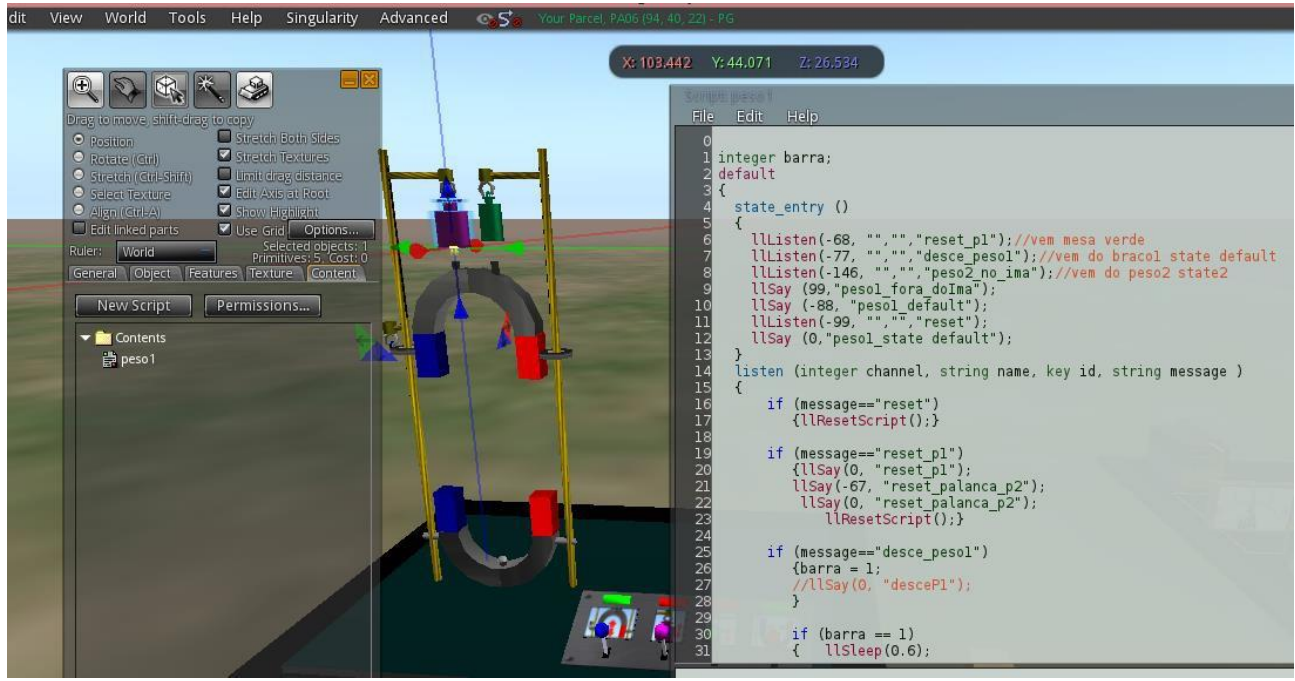

Fonte: o autor.

A experimentação ocorreu da seguinte forma:

a) $\mathrm{O}$ controle do experimento foi realizado pelo clique do mouse sobre cada uma das alavancas dispostas em um painel, liberando ou recolhendo o imã superior e as massas, ou invertendo horizontalmente a posição do imã inferior;

b) À medida que as massas foram posicionadas sobre o imã superior, este sofreu uma variação na posição vertical aproximando-se do ímã inferior, até assumir um estado de equilíbrio;

c) À medida que as massas foram retiradas do imã superior, este se afastou do imã inferior até adquirir novamente o equilíbrio;

d) Caso a alavanca vermelha (imã inferior) fosse acionada antes das demais, somente a alavanca azul (imã superior) estaria liberada para o acionamento, impedindo o posicionamento das massas sobre o imã superior. Após o acionamento da alavanca azul, o imã superior desceu livremente até ser atraído pelo imã inferior (figura 03).

Figura 03- Inversão da posição do imã inferior para atrair o imã superior.
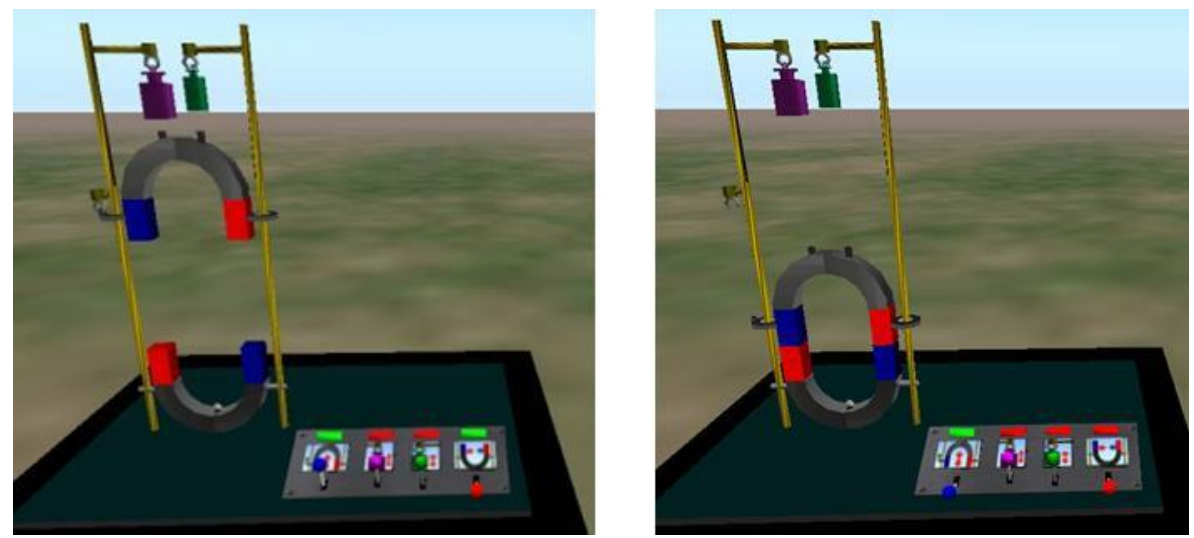

Fonte: o autor. 
O experimento foi projetado com base no seguinte fato: equilíbrio do imã superior e nos fatores: pesos relacionados às massas M1 e M2, força peso do imã superior e força de repulsão magnética. O desafio foi explicar as razões do imã superior (mesmo descendo livre) não encostar-se ao imã inferior (efeito da força de repulsão magnética). Com isso, esperou-se a compreensão, pelo sujeito, tanto dos fatores responsáveis pela atração e repulsão, quanto do sistema de equilíbrio formado pela força peso do imã superior e pela força de repulsão magnética entre os dois imãs, revelando traços do pensamento formal relacionado ao grupo INRC.

Em termos físicos, o imã superior estará em equilíbrio quando, tanto o momento linear (P) do seu centro de massa, quanto com o momento angular (L) em torno do centro de massa forem constantes, conforme a segunda lei de Newton para translação e rotação (figura 03).

Figura 03- Equilíbrio imã superior sem M1 e M2 e com M1 e M2
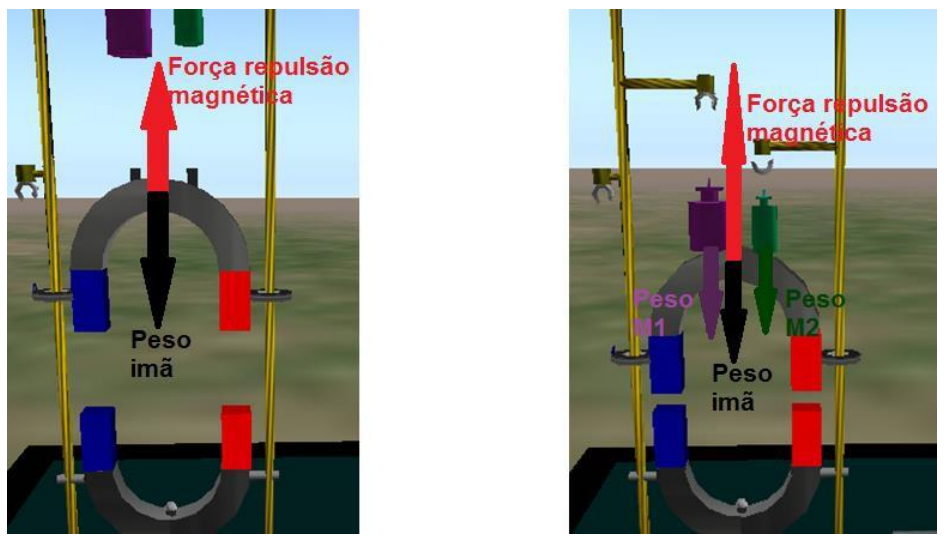

Fonte: o autor.

Equilíbrio transacional:

$\sum F$ ext $=\frac{\partial P}{\partial t}, \mathrm{P}$ constante $\rightarrow \frac{\partial P}{\partial t}=0, \sum F$ ext $=0$ (equilíbrio de forças)

Equilíbrio rotacional:

$\sum \tau e x t=\frac{\partial L}{\partial t}$, L constante $\rightarrow \frac{\partial P}{\partial t}=0, \sum \tau e x t=0$ (equilíbrio de torques)

A relação entre o experimento e o pensamento formal é apresentada através das transformações do real e suas respectivas operações (ação interiorizada ao nível do pensamento) proposicionais.

As transformações sobre a realidade foram do tipo:

I. DIRETA: Ação exercida pela sobreposição das massas no imã superior (coordenação de ações para aumentar o módulo das grandezas físicas de massa e peso);

II. INVERSA: Supressão da ação anterior pela retirada das massas do imã superior (diminuição das grandezas descritas no item I);

III. RECÍPROCA: Compensação entre a força peso do imã superior pela força de repulsão causada pelo campo magnético do imã inferior, (à medida que as massas são colocadas, ocorre uma movimentação e depois o equilíbrio da posição do imã superior); 
IV. CORRELATIVA: negação da ação anterior (ocorreria no caso de uma inversão da posição dos polos do imã inferior, causando uma força de atração magnética com mesma direção e sentido do peso do imã superior);

Das transformações acima, foram apresentadas as respectivas operações proposicionais do grupo INRC:

1) $I\left(\mathrm{p}_{1} \mathrm{~V} \mathrm{p}_{2}\right)=$ operação direta, representa dois valores diferentes da força peso do imã superior (causadas pela adição das massas).

2) $\mathrm{N}\left(\sim \mathrm{p}_{1} \bullet \sim \mathrm{p}_{2}\right)=$ operação inversa, ou seja, a supressão dos efeitos de $\mathrm{p}_{1}$ e $\mathrm{p}_{2}$ (representada pela retirada das massas do imã).

3) $\mathrm{R}\left(\sim \mathrm{p}_{1} \mathrm{~V} \sim \mathrm{p}_{2}\right)=$ operação recíproca, ou seja, a compensação dos efeitos de $\mathrm{p}_{1}$ ou $\mathrm{p}_{2}$ pela ação da força de repulsão levando ao equilíbrio (mesma direção e módulo, mas sentido inverso).

4) $\mathrm{C}\left(\mathrm{p}_{1} \bullet \mathrm{p}_{2}\right)=$ operação correlativa que nega a recíproca (anulação dos efeitos contrários desta). Isto se aplica no caso do imã inferior inverter a posição de seus polos objetivando atrair o imã superior, ter-se-ia então as forças peso e de atração magnética com o mesmo sentido.

O experimento foi aplicado a alunos do terceiro ano do Ensino Médio e a coleta de dados se deu pela gravação da manipulação do experimento no ambiente virtual através do emprego do programa CamStudio (camstudio.org/), o qual é um gravador de vídeo e áudio cuja função é capturar a tela do PC e gerar um arquivo de vídeo em formato avi.

Com o objetivo de "seguir" o pensamento do sujeito e facilitar a análise dos dados coletados, as indagações realizadas durante as atividades virtuais imersivas 3D foram baseadas no Método Clínico piagetiano (DELVAL, 2002).

A análise de dados buscou descobrir elementos relacionados à coordenação de ações de manipulação do dispositivo experimental, capaz apontar indícios do uso do pensamento formal, como a capacidade de realizar a dissociação de fatores via raciocínio hipotético-dedutivo, em conjunto com uma verificação de hipóteses (PIAGET; INHELDER, 1976).

\section{RESULTADOS E DISCUSSÃO}

Para aprimorar o experimento, este foi apresentado preliminarmente a dez (10) adolescentes (entre 11 e 15 anos) que, após a simulação, forneceram um retorno interessante. Inicialmente pensaram se tratar de um jogo, isto se justifica devido ao ambiente possuir uma interface gráfica muito similar aos jogos que permeiam a vida dos alunos. No inicio foi solicitado aos sujeitos a tentativa de identificar os componentes do experimento para uma adequação de linguagem entre entrevistador e entrevistado. Os imãs (superior e inferior) foram imediatamente reconhecidos, mas houve certa confusão sobre as suas denominações dos demais objetos, ocorrendo um discernimento maior somente após o acionamento das respectivas palancas. Quanto ao painel de controle, este foi facilmente intuído como o responsável pelo controle dos demais objetos do experimento. Com relação à funcionalidade das palancas, suas cores e os desenhos com setas de movimentação auxiliaram a relacionar os objetos sob a respectiva ação. No entanto, quando questionados quanto ao o que ocorreria quando da ativação das palancas, a maioria não soube antecipar os acontecimentos.

ANT $(13 ; 3)$ "O imã de cima encostou no imã de baixo? Não. Por que? Por causa que pra eles se juntarem deviam estar virado, o vermelho no azul e o azul no vermelho, porque assim eles se empurram." Após acionamento da palanca azul e liberação do imã 
superior, quando questionados sobre a razão deste não encostar-se ao imã inferior, foram feitas referencias às cores nas extremidades dos imãs, sem mencionar a explicação física. Foi relatado que da maneira como os imãs estavam dispostos (cores dos polos) eles estavam se "empurrado" mutuamente, denotando intuitivamente a questão da repulsão magnética.

ALI $(15 ; 2)$ "Se tu clicar na palanca rosa oque acontece? Eu não sei. Então clica. Ah, são pesos pra empurrar o imã mais pra baixo! $O$ imã desceu mais. Os imãs encostaram? Não, mas pesou bastante, se eu clicar no verde talvez encoste. Após o acionamento: não encostou!" $\mathrm{E}$ se fossem colocadas mais pesos? Eu acho que encostaria, mas a pressão deve ser forte pra não encostar assim. Quando solicitado a responder sobre oque ocorreria quando do acionamento das palancas verde e lilás, foi dito não saber qual funcionamento iria ocorrer, mas que estava relacionado com massas de mesmas cores. Quando do acionamento das massas, elas foram identificadas como "pesos" cuja função seria "empurrar o imã para baixo". Quando questionados sobre as razões do imã superior não encostar-se ao inferior, mesmo com a sobreposição da massa lilás, grande parte das respostas foi de que não haveria ainda peso suficiente para encostar e que a massa verde poderia fazer os imãs encostarem-se. Quando a sobreposição da massa verde não foi suficiente, foi questionado oque ocorreria com a sobreposição de outras massas e a resposta foi quê realmente o ima superior ia encostar no inferior. Um estudante fez referência a uma "forte pressão" entre os imãs para, mesmo com duas massas, não se encostassem, oque pode estar fazendo referência a intensidade da força de repulsão.

RIC $(11 ; 6)$ "Teve um aluno que falou o contrário, que se os imãs estivessem iguais (posição de repulsão) eles iriam se encostar. Eu acho que não, eu acho que só se o imã estiver assim: posiciona o imã inferior com os polos invertidos em relação ao superior. Se os imãs tiver assim eles vão. Assim como? Um oposto do outro." Por iniciativa própria, alguns estudantes colocaram as massas e o imã na posição inicial, de forma que a luz verde indicasse a liberação da palanca vermelha, não havendo surpresa quando a previsão da atração aconteceu realmente. Também foi relatado que naquele momento não precisaria mais os pesos, pois a função deles seria aproximar os imãs. Quando feita uma contra argumentação sobre a ocorrência da atração mesmo com os polos na mesma posição, foi dito que este pensamento estaria errado, pois a atração só ocorreria com os polos invertidos.

\section{CONCLUSÕES}

Como resposta a questão de pesquisa foi possível desenvolver, em um ambiente virtual imersivo 3D, um experimento físico cuja dinâmica representou as transformações do grupo INRC de Piaget. Devido a aprendizagem de Eletromagnetismo sofrer algum prejuízo pela dificuldade do estudante em exercer o raciocínio relacionado ao pensamento formal, acredita-se que experimentos regidos pelo funcionamento do grupo INRC possam ser mais desafiadores e estimulantes para a construção de conhecimento em tal área. O equilíbrio do imã superior se deveu à compensação entre as forças peso e de repulsão magnética, indicando a possibilidade e a necessidade da integração entre os adiantamentos da Física (Mecânica e Magnetismo), além de mostrar a perspectiva da reversibilidade por reciprocidade sem a formação de uma par ação e reação.

Relativo a estratégia construtivista empregada no ambiente imersivo, a Epistemologia Genética agiu como um pano de fundo para a teoria da Aprendizagem Experiencial, no sentido desta última atuar como um programa aplicativo 'rodando' a 
partir de um "sistema operacional" (Piaget). Pois, se a aprendizagem experiencial também está calcada na ação sobre o objeto do conhecimento, não seria possível ao sujeito passar pelas etapas do ciclo de Kolb sem movimentar suas estruturas cognitivas para adaptar-se ao novo.

Dessa forma, é possível que a Aprendizagem Experiencial possa ser compreendida a partir do conceito de aprendizagem desenvolvido por Piaget (1974), no qual esta é provocada e não espontânea e constitui-se em um processo limitado a um problema singular. A aprendizagem proveniente da teoria de Kolb parece corresponder então, a aquisição de um conhecimento novo e específico derivado do meio, conforme a Epistemologia Genética apregoa. É crível que esta aprendizagem seja, inicialmente, considerada stricto sensu se for adquirida em função da experiência e evoluir no tempo, mas não se descarta a ocorrência de outros modos de aquisição de conhecimento como a percepção ou a compreensão imediata. Também é considerada a possibilidade da constituição da aprendizagem lato sensu, desde que seja a união entre uma aprendizagem stricto sensu com um processo de auto-regulação que vise obter sucesso em uma ação ou operação. Oque provavelmente ocorra na etapa do Ciclo de Kolb denominada de Experiência Ativa, a qual pretende repercutir, na prática, as aprendizagens alcançadas ao longo do processo experiencial.

\section{REFERÊNCIAS BIBLIOGRÁFICAS}

AMARAL, E.M.H., ÁVILA, B., TAROUCO, L. Implementação de Laboratórios Virtuais no metaverso OpenSim. Renote. V11 n.1, p. 1-12, 2013.

BRASIL. Ministério da Educação. Secretaria de educação media e tecnologia. Parâmetros curriculares nacionais: Ensino Médio: Ciências da Natureza, Matemática e suas Tecnologias. Brasília: MEC/SEMTEC, 1999 b.

DELVAL, J. Introdução à Prática do Método Clínico, Ed. Artmed, 2002.

GREIS, L. K. Second Life: uma proposta de utilização pedagógica, 2007 disponívelem:<http://pead.ucpel.tche.br/revistas/index.php/colabora/article/viewFile/96/ 82>.Acesso em 10 de Marc. de 2018.

GRIMSHAW, M. The Oxford Handbook of Virtuality. OUP USA, 2014.

HERPICH, F., TAROUCO, L. Engajamento de Usuário em Mundos Virtuais: uma análise tórico-prática. Novas Tecnologias na Educação. V14 n.1, 2016.

JONASSEN, D., DAVIDSON M, COLLINS M. et. Al. Constructivism and Computer-M ediated Communication in Distance Education, 1995. Disponível em <http://www.c3l.uni-oldenburg.de/cde/media/readings/jonassen95.pdf >. Acesso em 15 de Out. 2017.

KOLB, D. A. Experiential Learning: Experience as the Source of $L$ earning and Development. Englewood Cliffs, N.J.: Prentice Hall, 1984.

MACEDO, S. H. LIMA, J.V. BIAZUS, M.C.V. Reflexões sobre o processo de Ensino-Aprendizagem de Eletromagnetismo. Novas Tecnologias e mediação pedagógica. Campinas: Papirus, 2000. p247-260.

MAYER, R, E. Multimedia learning. New York: Cambridge Univesity Press. 2001.

MELO, A. C. S. Transposição Didática do $M$ odelo de Huygens: uma proposta para a física escolar . Florianópolis, Disponível em: <http://www.ppgect.ufsc.br/base-dt/ufsc-ppgect-teses2010-ana-melo-integra.pdf>.

Acesso em: 01 abril de 2017. 
PIAGET, J. Fazer e compreender, Edições Melhoramentos- Editora da USP, São Paulo, 1978.

PIAGET, J. INHELDER, B. Da lógica da criança à lógica do adolescente, Livraria Pioneira Editora, São Paulo, 1976.

PIAGET, J. ; GRÉCO, P. Aprendizagem e conhecimento, Livraria Freitas Bastos, Rio de Janeiro, 1974.

TAVARES, R. RODRIGUES, G. L. SANTOS, J. N. ANDRADE, M. Eletromagnetismo: objetos de aprendizagem e a construção de significados baseados em um ambiente de múltiplas representações. XIX SBIE, 2008.

YIN, R. K. Case Study Methods. In: GREEN, J. L.;CAMILLI, G., et al (Ed.). Handbook of Complementary Methods in Education Research. Estados Unidos: Routledge, 2006. p.111-122. 